\title{
Los deberes inherentes al cargo de director de una sociedad anónima
}

\author{
Samuel Jair Véliz Ortiz*
}

Resumen. - A través del presente trabajo, el autor busca guiar al lector en el tema de los deberes fiduciarios inherentes al cargo de director según la Ley Nº 26887 - Ley General de Sociedades. Teniendo en cuenta el objetivo del artículo, el autor realiza un análisis de los motivos que sustentan la imposición de ciertos deberes para los directores en una sociedad anónima, el alcance de dichos deberes y la forma en que deben ser interpretados.

\begin{abstract}
Through this work, the author seeks to guide the reader in the matter of the fiduciary duties inherent to the position of director according to Law $\mathrm{N}^{0} 26887$ - Ley General de Sociedades. Considering the objective of the article, the author makes an analysis of the reasons that support the imposition of the article, the author makes an analysis of the reasons that support the imposition of certain duties for director in a corporation, the scope of such duties and how they should be interpreted.
\end{abstract}

* Abogado por la Universidad Católica de Santa María de Arequipa. Máster en Derecho de la Empresa por la Universidad de Navarra de España. Asociado del área corporativa del Estudio Payet, Rey, Cauvi, Pérez Abogados. Adjunto de docencia del curso de Sociedades Anónimas en la Pontificia Universidad Católica del Perú. 
En el presente artículo abordamos la temática de los deberes fiduciarios que la Ley No 26887 - Ley General de Sociedades (“LGS”) establece para los directores de una sociedad anónima. En primer lugar, analizamos los motivos que sustentan la imposición de deberes de conducta que deben cumplir los directores. Luego revisamos la forma en que la LGS regula dichos deberes y como los desarrolla la doctrina y como se encuentran regulados en el derecho comparado.

\section{Fundamentos de la necesidad de regular la actuación de los directores}

\subsection{Características esenciales de las corporaciones empresariales}

Previamente a introducirnos en el tratamiento de los deberes inherentes al cargo de director según nuestra LGS; resulta conveniente entender el sustrato que motiva la necesidad de regular la actividad y la conducta de los administradores de una sociedad anónima. Para ello, es propicio tener presente tres características esenciales de las sociedades anónimas.

Armour, Hansmann y Kraakman ${ }^{1}$ realizaron un estudio con el objeto de determinar una posible estructura común del Derecho de las corporaciones empresariales, o como se denomina también, Derecho Societario, en diferentes jurisdicciones. Los tres autores destacaron que, si bien existen claras diferencias entre corporaciones europeas, japonesas y americanas con respecto al gobierno corporativo, titularidad de acciones, el mercado de capitales y la cultura empresarial; existe una uniformidad sorprendente que subyace a la forma corporativa.

Es entonces que se puede señalar que existen cinco características estructurales principales de las corporaciones empresariales: (i) personalidad jurídica; (ii) responsabilidad limitada; (iii) acciones trasferibles; (iv) administración centralizada bajo la estructura de un directorio; y, (v) la propiedad del inversionista. Para los fines del presente trabajo, nos centraremos de forma concreta en la personalidad jurídica, responsabilidad limitada y la administración centralizada bajo la estructura de un directorio.

(i) Personalidad jurídica: Esta primera característica esencial de las corporaciones empresariales establece que la sociedad es en sí misma una persona para efectos legales y, en consecuencia, es capaz de celebrar contratos, poseer su propia propiedad; es capaz de delegar autoridad a sus agentes, y es capaz de demandar y ser demandado en su nombre².

El artículo 6 de la LGS reconoce que la sociedad adquiere personalidad jurídica desde su inscripción en el Registro y se mantendrá hasta que se

1 ARMOUR, John; HANSMAN, Henry y KRAAKMAN, Reiner. The Essential Elements of Corporate Law. What is Corporate Law? En KRAAKMAN, Reiner y otros. The Anatomy of Corporate Law. 2da. Edición Oxford. Oxford University Press. 2009.

2 Ídem. 
inscriba su extinción. De $\operatorname{Cossio}^{3}$ nos señala lo siguiente respecto a la personalidad jurídica de la sociedad anónima:

“Nos encontramos, por tanto, ante dos aspectos perfectamente diferenciados de la personalidad jurídica: una personalidad interior, fundada en la autonomía y elaborada dentro del campo del Derecho Público y una personalidad exterior, fundada en la titularidad única, fruto de la técnica del Derecho Privado. Solamente cuando ambos elementos se reúnen en un determinado ente colectivo puede afirmarse que existe una auténtica personalidad jurídica; esto es, una entidad que absorbe la individualidad de sus miembros, sometiéndolos al régimen de su autonomía, comportándose frente a los terceros como autentico sujeto de derechos y deberes".

Como conclusión de esta primera característica debemos resaltar que las sociedades tienen una personalidad propia que le permite ser titular de derechos y obligaciones.

(ii) Responsabilidad ilimitada: Esta segunda característica esencial impone una cláusula supletoria en los contratos entre la sociedad y sus acreedores mediante la cual los acreedores únicamente estarán limitados a efectuar reclamos contra los activos que sean propiedad de la sociedad y reconocer que no tienen derecho contra los activos de los accionistas de la sociedad que éstos poseen a su nombre ${ }^{4}$.

El artículo 51 de la LGS reconoce expresamente que el capital de la sociedad está representado por acciones nominativas y se integra por aportes de los accionistas, quienes no responden personalmente por las deudas sociales. Elías $^{5}$ nos señala lo siguiente sobre la responsabilidad limitada de los accionistas en una sociedad anónima:

“Otro rasgo típico de la sociedad anónima es la responsabilidad limitada. Debido a ella, los socios no responden personalmente por las deudas sociales. La única garantía que tienen los acreedores de la sociedad son los activos de la misma. En caso estos sean insuficientes para cubrir las deudas que haya contraído, los socios no responden por ellas."

Sobre esta característica debemos resaltar que si bien el capital de la sociedad se encuentra integrado por los aportes de los accionistas y que los accionistas son titulares de las acciones representativas del capital social; los accionistas no responderán con su patrimonio por las deudas sociales.

3 DE COSSIO, Alfonso. Instituciones de Derecho Civil. Tomo I. p. 127.

4 ARMOUR, John; HANSMAN, Henry y KRAAKMAN, Reiner. The Essential Elements of Corporate Law. What is Corporate Law? En KRAAKMAN, Reiner y otros. The Anatomy of Corporate Law. 2 da. Edición Oxford. Oxford University Press. 2009.

5 ELÍAS LAROZA, Enrique. Derecho Societario Peruano. La Ley General de Sociedades del Perú. Tomo I. p. 216. 
(iii) Administración centralizada bajo la estructura de un directorio: Otra característica esencial de las corporaciones es que generalmente la autoridad principal sobre asuntos corporativos recae en una junta de directores o un órgano de estructura similar elegido periódicamente por los accionistas de la sociedad. Ello genera que los accionistas de una sociedad anónima no tengan que estar obligatoriamente vinculados con la administración social como sucede en las sociedades personalistas; lo que conlleva que la administración social pueda encontrarse a cargo de personas especializadas en el rubro de actuación de la sociedad y que los accionistas puedan invertir en más de una sociedad.

El artículo 160 de la LGS recoge esta característica al señalar que no se requiere ser accionista para ser director a menos que el estatuto disponga lo contrario. Elías $^{6}$ nos indica al respecto lo siguientes:

"La perspectiva moderna de la administración societaria ha consagrado la disociación entre la titularidad del capital invertido y el control sobre la sociedad. En esa línea, la gestión y administración debe estar en manos de quienes resulten profesionalmente capacitados para desarrollar esas funciones. Por eso, no es requisito ser accionista para ser director".

Si bien nuestra legislación societaria reconoce en el artículo 247 que una sociedad anónima cerrada puede optar por no tener directorio, la administración social podrá estar especializada a través de la gerencia de la sociedad. Como principal punto a destacar en esta característica es que la administración de la sociedad podrá encontrarse a cargo de personas que no sean accionistas.

Es entonces que, tomando en consideración las tres características esenciales de las sociedades anónimas desarrolladas en los párrafos precedentes, es que podemos apreciar que si bien los accionistas son los inversionistas de la sociedad y por ello son propietarios de las acciones que representan el capital social; la sociedad tiene una personalidad jurídica propia y un interés social distinto al de los accionistas; siendo que la administración de la sociedad podrá estar a cargo de personas que no sean accionistas con la finalidad de lograr una especialización en la gestión social.

Es así como se puede apreciar claramente que existirá una relación de agencia entre los accionistas y los administradores de una sociedad anónima, situación que desarrollamos a continuación.

\subsection{Relación de agencia entre accionistas y administradores}

En una sociedad anónima, los accionistas que son los inversionistas y propietarios de las acciones que representan el capital de la sociedad delegarán a los

$6 \quad$ Ibid. p. 580. 
administradores de la sociedad (directores y gerentes) la capacidad para decidir y adoptar acciones en el marco de la actividad empresarial de la sociedad.

Es así como se genera una relación de agencia en la cual los accionistas serán los principales y los administradores serán los agentes. Jensen ${ }^{7}$ nos explica lo siguiente acerca de las relaciones de agencia:

“(U)na relación de agencia (es) un contrato bajo el cual una o más personaslos principales- contratan a una persona para que realice algún servicio en su beneficio que implica delegar algún grado de discreción al agente. Si ambas partes de la relación buscan maximizar su beneficio personal, hay buenas razones para pensar que el agente no siempre actuará en interés del principal".

Como bien lo señala Payet $^{8}$, la problemática de las relaciones de agencia radica en alinear la conducta de los agentes con los intereses de sus principales en situaciones en las que el agente tenga capacidad de actuar discrecionalmente y que enfrente situaciones en las que exista la posibilidad de utilizar dicha discreción para maximizar su beneficio personal a costa del beneficio de su principal.

Ahora bien, como lo desarrollamos en el apartado anterior del presente trabajo, los accionistas son los inversionistas de la sociedad y son éstos los que se encuentran interesados en enriquecerse a través de la sociedad, y por tanto la generación de valor patrimonial tiene que servir al objetivo de reparto final de esa riqueza entre los socios 9 .

Lo anterior responde al concepto tradicional de "interés" de la sociedad que radica que en que el objetivo del derecho corporativo y, por ende; la actuación de los encargados de la gestión social es asegurar que la sociedad sirva al mejor interés de sus accionistas; o de forma más específica, maximizar el rendimiento financiero de los accionistas.

No obstante, no se debe perder de vista que la sociedad tiene una personalidad jurídica propia distinta a la personalidad de los accionistas; siendo entonces que somos de la línea de que el objetivo del derecho corporativo y la finalidad de la actuación de los administradores de la sociedad es promover el bienestar agregado de todos los afectados por las actividades de una empresa, dentro de los cuales podemos encontrar a los accionistas, trabajadores, proveedores y clientes, así como terceros, como las comunidades locales ${ }^{10}$.

JENSEN, Michael. A Theory of the Firm. Cambridge: Harvard University Press, 2000, p. 85 y 86.

PAYET PUCCIO, José Antonio. Transacciones entre partes relacionadas. Revista IUS ET VERITAS $\mathrm{N}^{\circ} 48$, Julio 2014.

9 IBÁÑEZ JIMÉNEZ, Javier. El Derecho de Sociedades y el Empresario Societario. En: Fundamentos de Derecho Empresarial. Derecho de Sociedades. Tomo II.

10 ARMOUR, John; HANSMAN, Henry y KRAAKMAN, Reiner. The Essential Elements of Corporate Law. What is Corporate Law? En KRAAKMAN, Reiner y otros. The Anatomy of Corporate Law. 2da. Edición Oxford. Oxford University Press. 2009. 
Ahora bien, existe una serie de alternativas para alinear la conducta de los administradores de la sociedad con los intereses de los accionistas y de la propia sociedad para tratar la problemática de las relaciones de agencia; como son la adopción de políticas de buen gobierno corporativo, mecanismos contractuales como el otorgamiento de bonos por rendimiento y las obligaciones a cumplir por los directores establecidas legalmente.

Es entonces que la problemática de la relación de agencia propia de la actividad que desarrollan los administradores de una sociedad anónima da lugar a que la LGS imponga ciertos deberes básicos a los directores de una sociedad anónima.

\section{Deberes fiduciarios de los directores}

\subsection{El cargo de director}

El artículo 152 de la LGS establece que la administración de una sociedad se encuentra a cargo del directorio y de los gerentes. Por su parte, el artículo 153 de la LGS señala que el directorio es un órgano colegiado elegido por la junta general de accionistas de la sociedad.

Es así como el directorio es el órgano de gestión y representación de una sociedad, conformado por una pluralidad de miembros -directores-, designados por la junta general de accionistas. En este sentido, los directores tienen la labor de adoptar conjuntamente acuerdos relacionados al manejo de la sociedad conforme a su objeto social dentro de los límites que el estatuto social le haya impuesto a sus atribuciones y facultades. Todo acuerdo adoptado por los directores será en nombre del directorio de la sociedad y no a título personal.

\subsection{Deberes inherentes al cargo de director según la LGS}

El artículo 171 de la LGS establece lo siguiente respecto al ejercicio del cargo de director y resulta el principal artículo en materia de deberes que deben cumplir los directores:

“Artículo 171.- Ejercicio del cargo y reserva

Los directores desempeñan el cargo con la diligencia de un ordenado comerciante y de un representante leal.

Están obligados a guardar reservar respecto de los negocios de la sociedad y de la información social a que tengan acceso, aún después de cesar en sus funciones".

Del artículo citado podemos obtener que los directores de una sociedad tienen tres deberes inherentes a su cargo; los cuales son: (i) deber de diligencia, (ii) deber de lealtad: y (iii) deber de reserva.

\section{a) Deber de diligencia}


El primer deber inherente al cargo de director que se desprende del artículo 171 de la LGS es el deber de diligencia y conforme lo señala el artículo en cuestión, los directores deben actuar con la diligencia de un "ordenado comerciante"; siendo que este concepto hace referencia al patrón de diligencia de un hombre de negocios. Elías ${ }^{11}$ al respecto nos señala que:

"Aunque las premisas de "ordenado comerciante" y "representante leal" no son definidas ni desarrolladas por la norma, si se encuentran plenamente aplicadas al desempeño del cargo, o sea a las funciones de gestión y de representación que, como miembros de un órgano administrador de la sociedad, los directores deben cumplir diligentemente con la finalidad de llevar a cabo el objeto social. Debemos destacar que el desempeño del cargo con las cualidades de un ordenado comerciante en la nueva LGS es más una norma jurídica de conducta que un parámetro para juzgar la responsabilidad de los directores".

Como lo señala Elías, el término de "ordenado comerciante" no se encuentra definido por la LGS; por lo que resulta necesario recurrir a la doctrina y al derecho comparado para conocer los alcances de dicho concepto.

La Ley de Sociedades de Capital ${ }^{12}$ que regula las sociedades mercantiles en España establece en su artículo 225 que los administradores deben desempeñar su cargo y cumplir los deberes impuestos por las leyes y los estatutos con la diligencia de un "ordenado empresario".

Si bien la legislación peruana utiliza el concepto de "ordenado comerciante" como estándar de diligencia de los directores y la legislación española utiliza el concepto de "ordenado empresario" consideramos que ambos conceptos son análogos.

Es importante destacar que el artículo 226.1 de la Ley de Sociedades de Capital española señala lo siguiente con respecto a la discrecionalidad empresarial de la que gozan los administradores:

Artículo 226. Protección de la discrecionalidad empresarial.

“1. En el ámbito de las decisiones estratégicas y de negocio, sujetas a la discrecionalidad empresarial, el estándar de diligencia de un ordenado empresario se entenderá cumplido cuando el administrador haya actuado de buena fe, sin interés personal en el asunto objeto de decisión, con información suficiente y con arreglo a un procedimiento de decisión adecuado (...)" (Énfasis agregado).

11 ELÍAS LAROZA, Enrique, Derecho Societario Peruano. La Ley General de Sociedades del Perú. Tomo I. p. 357.

12 Real Decreto Legislativo 1/2010, de 02 de julio, por el que se aprueba el texto refundido de la Ley de Sociedades de Capital. 
Paz-Ares ${ }^{13}$ nos explica que un administrador actuará como un ordenado empresario cuando concurran los siguientes supuestos:

- Que la decisión empresarial se haya tomado con la suficiente información, siguiendo los procedimientos formalmente establecidos;

- Que el administrador haya actuado en defensa del interés social, esto es, que no tenga interés personal en cualquier consecuencia directa o colateral de la decisión;

- $\quad$ Que se trate de decisiones objetivamente razonables y adecuadas para la satisfacción del interés social.

Asimismo, también resulta pertinente apuntar que Paz-Ares señala que "el deber de diligencia del "ordenado empresario"- exige que los administradores inviertan una determinada cantidad de tiempo y esfuerzo y desplieguen un cierto nivel de pericia en la gestión o supervisión de la empresa a fin de maximizar la producción de valor"14.

En el derecho anglosajón también encontramos que los miembros de un board of directors se encuentran sujetos al "duty of care" que resulta ser la equivalencia del deber de diligencia previsto en nuestra normativa nacional15; y así como la legislación española protege la discrecionalidad empresarial de los directores, el derecho anglosajón también reconoce el "business judgement rule" de los miembros del board of directors ${ }^{16}$.

Es en base a lo expuesto anteriormente que el deber de diligencia de los directores se configura como una obligación de medios y no como una obligación de resultados en el desempeño de su cargo. Lo anterior responde a que la actividad

13 PAZ-ARES, Cándido. La responsabilidad de los administradores como instrumento de gobierno corporativo. En: Revista IUS ET VERITAS N² 27. 2003. P. 204.

14 PAZ-ARES, Cándido. Deberes fiduciarios y responsabilidad de los administradores (Reflexiones para la reforme legal Latinoamericana. The Third Meeting of the Latin American Corporate Governance Roundtable. Conferencia llevada a cabo por la Bolsa Mexicana de Valores. Ciudad de México, 2012.

15 CLARK, Robert Charles. Corporate Law. Little, Brown and Company Law Book Division. Boston, p. 123.

Traducción de: "Statutes and case law say that directors and officers owe their corporations a duty of care: They must exercise that degree of skill, diligence, and care that a reasonably prudent person would exercise in similar circumstances. At times, some authorities have applied the stricter formulation that the directors or officer must act as a reasonably prudent person would act in the conduct of his own affairs. It is doubtful whether this difference in standard has affected the outcome of cases. In any event, by analogy to the duty of care concept used in tort law, violation of the director's or officer's duty of care is frequently described as negligence".

16 Ídem.

Traducción de: "In a sense, the business judgement rule is just a corollary of the usual statutory provision that it is the directors who shall manage the corporation. The rule is simply that the business judgement of the directors will not be challenged or overturned by courts or shareholders, and the directors will not be challenged or liable for the consequences of their exercise of business judgement - even for judgments that appear to have been clear mistakes unless certain exceptions apply. Put another way, the rule is "a presumption that in making a business decision, the director of a corporation acted on an informed basis in good faith an in the honest belief that the action was taken in the best interests of the company". 
empresarial y las decisiones adoptadas por los directores son "riesgosas" por naturaleza; en el sentido que nada asegura que la sociedad vaya a obtener ganancias producto de las decisiones que adopten los directores.

Consideramos que resulta correcto establecer que el cumplimiento del deber de diligencia por los directores no se puede juzgar aisladamente por los resultados que hayan tenido las acciones adoptadas y acuerdos tomados en el directorio; sino que el cumplimiento de este deber debe circunscribirse en que los directores hayan sido lo suficientemente diligentes en su actuación. Es por ello que consideramos que resultaría prudente que la LGS reconozca expresamente la protección a la discrecionalidad empresarial de los administradores de una sociedad.

\section{b) Deber de lealtad}

El segundo deber inherente al cargo de director que se desprende del artículo 171 de la LGS es el deber de lealtad. Conforme lo señalamos anteriormente, el concepto de "representante leal" tampoco ha sido desarrollado por la LGS; sin embargo, dicho concepto hace referencia a que el director no debe priorizar su propio interés por encima del de la sociedad y que debe evitar incurrir en situaciones de conflicto de interés.

Debemos precisar que pese a que no existe un listado de las obligaciones que se desprenden del deber de lealtad en nuestra LGS como si sucede en la legislación societaria española como explicaremos más adelante; los artículos 179 y 180 de la LGS representan obligaciones propias del deber de lealtad. Es así como el artículo 179 de la LGS establece que los directores únicamente pueden celebrar con la sociedad contratos que versen sobre operaciones que normalmente realice la sociedad con terceras personas y que se hayan celebrado en condiciones de mercado.

Asimismo, el artículo 179 de la LGS únicamente permite que la sociedad otorgue préstamos o créditos, o, constituya garantías a favor de los directores cuando se traten de operaciones que la sociedad usualmente celebre con terceros. Los contratos, créditos, préstamos o garantías que no reúnan los requisitos detallados previamente deberán ser aprobados con antelación por el directorio y con el voto favorable de al menos dos tercios de sus miembros. En caso se celebren actos en contravención de lo dispuesto por el artículo 179, los directores serán solidariamente responsables ante la sociedad y terceros acreedores.

Por su parte, el artículo 180 de la LGS prohíbe que los directores adopten acuerdos que vayan en contra del interés social y que respondan a sus propios intereses o de personas relacionadas. De igual manera, los directores no podrán usar en beneficio propio o de terceros relacionados las oportunidades comerciales de las que tuviesen conocimiento por el ejercicio de su cargo, ni tampoco podrán participar por su cuenta o por cuenta de terceros actividades que compitan con la 
sociedad; salvo que la sociedad los haya exonerado de tal obligación de forma expresa.

El artículo 180 resulta un artículo importante en el deber de lealtad de los directores; ya que señala que aquellos directores que tengan un interés en contrario al de la sociedad deberán manifestarlo y deberán abstenerse de formar parte de la deliberación y la adopción del acuerdo respectivo.

En caso algún director contravenga lo dispuesto por el citado artículo 180 de la LGS será responsable de los daños y perjuicios que se hubiesen causado a la sociedad y el directorio y/o la junta general de accionistas quedarán facultado para removerlo de su cargo a propuesta de cualquier director o accionistas.

La LGS utiliza el concepto de "interés en conflicto" en el marco de la suspensión del derecho de voto para los accionistas en la Junta General de Accionistas en el artículo 133 y el concepto de "interés en contrario" en el marco del Directorio en el artículo 180; por lo que parecería que el legislador tuvo la intención de distinguir dos tipos de situaciones de conflicto. Al respecto, Elías ${ }^{17}$ explica lo siguiente:

“El concepto fundamental de la norma es el interés en conflicto. Si bien existen al respecto muchas opiniones, no es fácil establecer una definición precisa que permita interpretar los casos concretos que se presentan. Por ello, muchas legislaciones guardan silencio, otras lo dejan a criterio de la doctrina o de la jurisprudencia y otras, como la nuestra, establecen el principio sin definirlo. (...)

Nuestra ley, en el artículo bajo comentario, utiliza la expresión de interés en conflicto que, en nuestra opinión, es más clara y explícita que la de interés en contrario. Lo segundo tiene una connotación menos grave que lo primero".

No obstante, de la redacción de la LGS no se puede obtener la definición de "interés en conflicto", la definición de "interés en contrario" ni la distinción entre ambos conceptos. En nuestra opinión, consideramos y sostenemos la teoría que se debe entender que existe interés en conflicto o interés en contrario, en toda aquella situación en la que exista una relación familiar, financiera, profesional, laboral u otra relación que razonablemente podría esperarse que afecte negativamente la objetividad del juicio del accionista y/o director al participar en la acción a ser tomada ${ }^{18}$.

También resulta necesario poner énfasis en lo previsto por el segundo párrafo del artículo 173 de la LGS con respecto a que los directores elegidos por un grupo o clase de accionistas tienen los mismos deberes con la sociedad y los demás

17 ELIAS LAROZA, Enrique, op. cit., p. 503-504.

18 HILL, Clair y MCDONELL, Brett. Sanitizong Interested Transactions. Delaware Journal of Corporate Law, Vol. 36, p. 912. 
accionistas que los directores restantes y su actuación no puede limitarse a defender los intereses de quienes los eligieron.

Es así como el artículo 173 de la LGS resulta gravitante para establecer que si bien existe una relación de agencia entre accionistas y directores; la cual se puede ver incluso más clara en los casos en que existan directores designados por determinados accionistas; la actuación de los directores no se podrá limitar a proteger o maximizar los intereses de los accionistas únicamente, sino que su actuación debe estar orientada siempre en el interés social.

Ahora bien, en el derecho comparado podemos encontrar que el artículo 227.1 de la Ley de Sociedades de Capital española precisa que los administradores deberán desempeñar su cargo con la lealtad de un fiel representante, obrando de buena fe y en el mejor interés de la sociedad. El artículo 228 de la Ley de Sociedades de Capital española establece determinadas obligaciones básicas que se desprenden del deber de lealtad, las cuales son:

- No ejercitar sus facultades con fines distintos de aquéllos para los que le han sido concedidas.

- Guardar secreto sobre las informaciones, datos, informes o antecedentes a los que haya tenido acceso en el desempeño de su cargo, incluso cuando haya cesado en él, salvo en los casos en que la ley lo permita o requiera.

- Desempeñar sus funciones bajo el principio de responsabilidad personal con libertad de criterio o juicio e independencia respecto de instrucciones y vinculaciones de terceros.

- Adoptar las medidas necesarias para evitar incurrir en situaciones en las que sus intereses, sean por cuenta propia o ajena, puedan entrar en conflicto con el interés social y con sus deberes para con la sociedad.

Paz-Ares ${ }^{19}$ al abordar el deber de lealtad de los administradores nos explica lo siguiente:

“El deber de lealtad obliga al administrador a no desviar valor de la esfera social a la esfera personal y, por tanto, excluye por definición la posibilidad de cualquier forma de alineamiento natural de intereses. El incumplimiento sólo depara al administrador beneficio (a mayor incumplimiento, mayor beneficio); no le impone ningún coste, pues es un juego meramente redistributivo (lo que se lleva una parte lo pierde la otra); en definitiva".

19 PAZ-ARES, Cándido. La responsabilidad de los administradores como instrumento de gobierno corporativo. En: Revista IUS ET VERITAS N²7. 2003. p. 208. 
En el derecho anglosajón también encontramos que los miembros de un board of directors se encuentran sujetos al "duty of loyalty" que resulta ser la equivalencia del deber de lealtad previsto en nuestra normativa nacional ${ }^{20}$.

Por lo tanto, el deber de lealtad impone a los directores de una sociedad anónima la obligación referida a que sus decisiones y actuaciones siempre deben estar orientadas a velar por el interés de la sociedad y su actuación no debe centrarse en su interés personal o de terceros relacionados ni tampoco limitarse a resguardar el interés de un determinado grupo de accionistas.

Si bien parecería claro que los directores deben buscar maximizar el interés de la sociedad; debemos poner en relieve lo apuntado anteriormente en el presente artículo en el sentido que la definición tradicional del interés social consiste en que el interés de la sociedad se centra en maximizar el rendimiento financiero de los accionistas. No obstante, también existe la corriente doctrinaria basada en que la sociedad, al tener una personalidad jurídica propia distinta a la personalidad de sus accionistas, su interés estará orientado en lograr el bienestar de todos sus stakeholders (accionistas, trabajadores, proveedores, comunidad).

Nosotros nos encontramos en la línea de que el interés de una sociedad no puede estar limitado únicamente en maximizar los intereses económicos de los accionistas, sino que las decisiones de los administradores de la sociedad deben tomar en consideración todos los grupos de interés de la sociedad. Sin perjuicio de lo anterior, también debe tenerse especial cuidado en no convertir el interés de la sociedad en un concepto difuso; ya que también es innegable que los accionistas tienen el derecho legítimo de obtener ganancias producto de su inversión en la sociedad.

\section{c) Deber de reserva}

Por último, los directores en virtud del artículo 171 de la LGS se encuentran obligados a mantener confidencialidad respecto de los negocios de la sociedad y de la información social a la que tuviesen acceso. Esta obligación se extiende incluso después de que hayan cesado en sus funciones. Si bien el presente trabajo se encuentra centrado principalmente en lo previsto en la LGS, el deber de reserva

20 CLARK, Robert Charles. Corporate Law. Little, Brown and Company Law Book Division. Boston, p. 141:

Traducción de: "Directors, officers, and, in some situations, controlling shareholders owe their corporations, and sometimes other shareholders and investors a fiduciary duty of loyalty. This duty prohibits the fiduciaries from taking advantage of their beneficiaries by means of fraudulent or unfair transactions. They may not abuse the beneficiaries in situations in which they have a conflict of interest. In some contexts, they may act improperly simply by maintaining a state of affairs in which they have a conflict of interest. Most importantly, this general fiduciary duty of loyalty is a residual concept that can include factual situations that no one has foreseen and categorized" 
de los administradores se ve acentuado en las sociedades que tengan valores inscritos en el Registro Público del Mercado de Valores.

De acuerdo con los artículos 41 y 43 del D.S. N 093-2002-EF - Texto Único Ordenado de la Ley de Mercado de Valores ("LMV”), se presume que los directores poseen información privilegiada del emisor y por ende están prohibidos de (i) revelar o confiar información privilegiada a otras personas hasta que ésta se divulgue al mercado, (ii) recomendar la realización de las operaciones con valores respecto de los cuales se tiene información privilegiada, y, (iii) hacer uso indebido y valerse de manera directa o indirecta, en beneficio propio o de terceros, de la información privilegiada.

El artículo 40 de la LMV establece que se debe entender como "información privilegiada" a cualquier información referida a un emisor, a sus negocios o a uno o varios valores por ellos emitidos o garantizados, no divulgada al mercado; y cuyo conocimiento público por su naturaleza, sea capaz de influir en la liquidez, el precio o la cotización de los valores emitidos.

También tiene consideración de información privilegiada los hechos o negociaciones en curso que se hayan decidido mantener en reserva debido a que pueden acarrear perjuicio al emisor y que hayan sido calificados como información reservada mediante acuerdo adoptado por no menos de las tres cuartas partes de los miembros del directorio conforme lo previsto por el artículo 34 de la LMV.

Si bien hemos desarrollado principalmente el deber de reserva que deben cumplir los directores de sociedades que tengan valores inscritos en el Registro Público del Mercado de Valores con la finalidad que el lector pueda distinguir la naturaleza del deber de reserva y como se diferencia principalmente del deber de lealtad; no se debe perder de vista que este deber es aplicable a todas las sociedades anónimas y tiene como objetivo principal evitar que los directores se vean beneficiados personalmente con la información de la sociedad en detrimento de ésta y evitar situaciones en que terceros se vean beneficiados en perjuicio de la sociedad por la difusión de parte de los directores de información relativa a los negocios de la sociedad.

\section{Consideraciones finales}

En el presente artículo hemos podido apreciar que la LGS regula los deberes inherentes al cargo de director con la finalidad de dar tratamiento a la problemática de la relación de agencia propia entre accionistas y directores. No obstante, consideramos que resulta conveniente que exista un mayor detalle en la regulación de los deberes fiduciarios de los administradores; ya que como hemos visto; es necesario complementar lo desarrollado por la LGS con doctrina especializada en la materia y con lo previsto en el derecho comparado.

En línea de lo señalado en el párrafo anterior, resaltamos las innovaciones legislativas propuestas por el anteproyecto de la Ley General de Sociedades 
elaborado por el Grupo de Trabajo conformado por R.M. Nº018-2017-JUS y el cual fue publicado el 4 de septiembre en la página web del Ministerio de Justicia y Derechos Humanos y el 13 de septiembre en el Diario Oficial "El Peruano".

En el anteproyecto de la Ley General de Sociedades se prevé que un mayor detalle de los deberes fiduciarios de los directores ya que se expresa las obligaciones que se derivan de estos deberes, se propone un tratamiento más completo en la suspensión del derecho de voto en casos de conflictos de interés del director, se reconoce de manera expresa la protección de la discrecionalidad empresarial de los administradores sociales, entre otros puntos.

Por último, queremos resaltar al lector que los deberes regulados por la LGS son complementados por diversas normas específicas que desarrollan las obligaciones que deben cumplir los directores, tales como en el ámbito tributario o incluso penal. Por lo tanto, el estudio de los deberes inherentes al cargo de director no debe limitarse únicamente a lo previsto por la LGS. 